\title{
Immunohistochemical Detection of the Cytoskeletal Components in Gastric Parietal Cells
}

\author{
Daisuke Wakamatsu ${ }^{1}$, Shinichiro Tsuyama ${ }^{2}$, Rie Maezono ${ }^{2}$, Kenji Kato ${ }^{1}$, Shunji Ogata', \\ Sonshin Takao ${ }^{3}$, Shoji Natsugoe ${ }^{1}$, Takashi Aikou ${ }^{1}$ and Fusayoshi Murata ${ }^{2}$ \\ ${ }^{1}$ Department of Surgical Oncology and Digestive Surgery, ${ }^{2}$ Department of Structural Cell Biology, Kagoshima University Graduate \\ School of Medical and Dental Sciences and ${ }^{3}$ Laboratory for Bioengineering \& Transplantation, Research Center for Life Science \\ Resources, Kagoshima University, 8-35-1 Sakuragaoka, Kagoshima 890-8544, Japan
}

Received March 7, 2005; accepted October 12, 2005

Gastric parietal cells are characterized by intracellular canaliculi with many microvilli and tubulovesicles. These membranous structures are continuous and change in volume according to gastric acid secreting or resting state. Morphological changes are induced by cytoskeletal actin. Actin filaments are anchored to the cell membrane via ezrin. This study aimed to ascertain whether morphological changes were related to the nature of ezrin molecules, which were either phosphorylated or non-phosphorylated. Rat stomach tissues were rapid-frozen followed by freeze-substitution and embedding in paraffin for light microscopy. Also, the specimens were high pressure-frozen, freeze-substituted and embedded in Epon 812 or Lowicryl $\mathrm{K} 4 \mathrm{M}$ for electron microscopy. Sections from paraffin or Lowicryl K4M were stained with anti- $\mathrm{H}^{+} \cdot \mathrm{K}^{+}$-ATPase antibodies, anti-phosphorylated or non-phosphorylated ezrin antibodies, and antiactin antibody. The $\mathrm{H}^{+\cdot} \mathrm{K}^{+}$-ATPase was distributed on the intracellular canaliculi and tubulovesicles. The intracellular canaliculi were labeled with anti-phosphorylated ezrin antibodies in fed (gastric acid secreting state) rats. These were stained weakly in starved (gastric acid resting state) rats. Anti-nonphosphorylated ezrin antibodies hardly stained these organelles in either state. A possible explanation is that the phosphorylation of ezrin molecules is related to the reciprocal membranous transformation between intracellular canaliculi and tubulovesicles.

Key words: gastric gland, parietal cell, $\mathrm{H}^{+} \cdot \mathrm{K}^{+}$-ATPase, cytoskeleton, high-pressure freezing

\section{Introduction}

The gastric gland is divided into four segments: the pit, isthmus, neck and base. After mitosis at a proliferation site in the isthmus, the cells migrate and differentiate bidirectionally to the luminal surface and the glandular base [8$13,32,33]$. The component cells of the gland are surface mucous cells, pit cells, undifferentiated progenitor cells, mucous neck cells, parietal cells, chief cells and endocrine cells. The parietal cells are found throughout the deep pit and gland, and are characterized by intracellular canaliculi with many microvilli and tubulovesicles in the cytoplasm

Correspondence to: Shinichiro Tsuyama, Department of Structural Cell Biology, Kagoshima University Graduate School of Medical and Dental Sciences, 8-35-1 Sakuragaoka, Kagoshima 890-8544, Japan. E-mail: stsuyama@m.kufm.kagoshima-u.ac.jp
$[6,27-29]$. The cells also have numerous distinct mitochondria, which increase in size with starvation [20].

It is well known that parietal cells play a major role in gastric acid secretion, showing differences in ultrastructural and cytochemical features between fed and starved states. The tubulovesicles are composed of an intracytoplasmic tubule-mass similar to sER beneath the cell membrane, which is connected to the intracellular canaliculi membrane $[28,29]$. They shift in volume according to the physiological state, and fed or starving state. It is considered that the intracellular canaliculi and tubulovesicles are mutually transformable structures. The fed or starved state corresponds to the active or inactive phase of gastric acid secretion. The proton pump $\mathrm{H}^{+} \cdot \mathrm{K}^{+}$-ATPase is active only on the luminal surface, but is inactive in cytoplasmic tubulovesicles. Basically, the parietal cells transform the morphological structures between the active and resting phase. In the active 
phase, intracellular canaliculi are dilated, and the tubulovesicle mass is narrow $[1,15,18,19,22,28,29]$. On the other hand, intracellular canaliculi decrease and tubulovesicles increase in the resting phase. It is believed that the initiation of these morphological changes is induced by cytoskeletal actin. Actin filaments are anchored to CD44 in cell membranes via ezrin molecules [7, 34, 35].

Cryofixation is considered to be superior with regard to structural preservation and retention of soluble components than conventional chemical fixation. In conventional chemical fixation, each processing step with organic solvents induces ultrastructural and molecular compositional changes due to denaturation or extraction of cell components. In cryofixation, it is thought that these phenomena are minimized because any ultrastructural damage or molecular denaturation is immobilized by freezing for a very short time. Among the cryofixation procedures, the rapid freezing method (especially, metal contact method) has been used frequently [5, 17, 27]. However, as the range of vitreous freezing is less than $20 \mu \mathrm{m}$ deep from the specimen surface, this method cannot deal with a large tissue volume. It is not adequate for electron microscopy, but the depth of vitreous freezing is not an obstacle for light microscopic observation. In contrast, the high-pressure freezing method permits greater depth of vitreous freezing, to more than $100 \mu \mathrm{m}$ from the tissue surface $[16,26]$. We have previously reported the morphological changes that occur between the two phases at the ultrastructure level using the high pressure freezing fixation method $[28,29]$. In the present study, the distribution of ezrin molecules was localized in the rat fundic gland by rapid freezing method at the light microscopic level. In addition to the ultrastructural transformation, the cytoskeletal components were examined using high pressure freezing followed by the freeze-substitution technique during the feeding and starved states. The main purpose of this study was to ascertain how morphological changes are related to the nature of ezrin molecules, which are either phosphorylated or non-phosphorylated [34, 35].

\section{Materials and Methods}

\section{Antibodies}

Rabbit antibodies against the $\alpha$ - and $\beta$-subunits of $\mathrm{H}^{+} \cdot \mathrm{K}^{+}$-ATPase (Immunogen: C-terminal synthetic-peptide based on porcine $\mathrm{H}^{+} \mathrm{K}^{+}$-ATPase sequence) were purchased from Calbiochem-Novabiochem (San Diego, CA, USA). These antibodies were used at 1:50 dilution in phosphate buffered saline (PBS). Rabbit anti-phosphorylated ezrin antibody and polyclonal rabbit anti-actin antibodies were from Chemicon International (Temecula, CA, USA), and monoclonal mouse anti-ezrin (nonphosphorylated) antibody was from Covance (Denver, PA, USA). The former anti-phosphorylated ezrin antibody recognizes $\mathrm{Thr} 567$ phosphorylated ezrin and does not cross-react with other related phospho proteins. The latter anti-ezrin antibody reacts with non-phosphorylated ezrin, showing a single band at $80 \mathrm{kD}$ on Western blots. The anti-actin antibody recognizes cytoplasmic actin but not muscle actin. The antiphosphorylated and non-phosphorylated ezrin antibodies were diluted $1: 10$ or 20 in PBS and the anti-actin antibody was used at 1:10 dilution. These primary antibodies were confirmed to show cross-reactivity against rat tissues. Biotinylated goat anti-rabbit $\mathrm{IgG}$ and rabbit anti-mouse $\mathrm{IgG}$ antibodies were obtained from DAKO A/S (Glostrup, Denmark). These secondary biotinylated antibodies were used at 1:100 dilution in PBS. Horseradish peroxidase (HRP)conjugated streptavidin and colloidal gold (CG)-conjugated streptavidin were from BioGenex (San Ramon, CA, USA) and British BioCell International (Cardiff, UK), respectively. The HRP-conjugated streptavidin was used at 1:100 dilution in Tris-buffered saline (TBS) and CG-conjugated streptavidin at 1:10 dilution in PBS, respectively.

\section{Tissue preparation}

Male Wistar rats, weighing 250-300 g, were obtained from Kyudo (Kumamoto, Japan). The rats were maintained before treatment under standard conditions according to the guidelines of the Animal Center of Kagoshima University. They were divided into two groups of five rats each. One group was fed a standard diet ad libitum and the other was starved for $48 \mathrm{hr}$ with free access to water. The rats were anaesthetized intraperitoneally with Nembutal (sodium pentobarbital) and the abdominal cavity was opened. The $\mathrm{pH}$ value of the luminal gastric juice was measured using test papers. Cryofixation was then performed as follows. Briefly, small pieces of stomach tissue were removed and cryofixed with a rapid freezing device, RF-6 (Eiko, Japan) using liquid propane cooled with liquid nitrogen for light microscopy. Then, the specimens were freeze-substituted with acetone containing $2 \%$ acrolein for $72 \mathrm{hr}$ and embedded in paraffin. For electron microscopy, small pieces of stomach tissue were high-pressure frozen with a high-pressure freezing machine, HPM 010 (Bal-Tec, Liechtenstein). High-pressure freezing was accomplished in a 2,100 bar atmosphere. The frozen specimens were transferred immediately into liquid nitrogen and then freeze-substituted in acetone containing $1 \%$ osmium or $2 \%$ acrolein for $72 \mathrm{hr}$, and embedded in Epon 812 or Lowicryl $\mathrm{K} 4 \mathrm{M}$ at $-35^{\circ} \mathrm{C}$, respectively $[28,29]$.

\section{Immunohistochemistry on light microscopy}

Sections $4 \mu \mathrm{m}$ thick were obtained with a Jung slidingmicrotome and mounted on silanized glass slides. Specimens were deparaffinized, rehydrated, rinsed in tap water, followed by treatment with $0.3 \%$ hydrogen peroxide in methanol to block endogenous peroxidase activity. After a rinse in PBS ( $\mathrm{pH} 7.4$ ), they were covered with $1 \%$ bovine serum albumin (BSA) in PBS to block nonspecific background staining. Then, specimens were incubated with the primary antibodies (rabbit anti- $\alpha$ - or $\beta$-subunits of $\mathrm{H}^{+} \cdot \mathrm{K}^{+}$ATPase antibodies, rabbit anti-phosphorylated ezrin antibody or mouse anti-non (de)phosphorylated ezrin antibody and rabbit anti-actin antibody) overnight at $4^{\circ} \mathrm{C}$, followed by the secondary antibodies (biotinylated goat anti-rabbit IgG or rabbit anti-mouse IgG antibodies) for $1 \mathrm{hr}$ at room 
temperature, and finally labeled with HRP-conjugated streptavidin for $1 \mathrm{hr}$. A DAB reaction was performed using Graham-Karnovsky's medium for 5-10 min [4]. Sections were then rinsed in distilled water, counterstained with Mayer's hematoxylin, dehydrated in a graded ethanol series and cleared in xylene, and finally mounted with Eukitt (O. Kindler, Germany).

\section{Immunocytochemistry on electron microscopy}

Semi-thin sections were cut perpendicular to the freezing surface and then stained with $0.1 \%(\mathrm{w} / \mathrm{v})$ toluidine blue in $1 \%$ borax aqueous solution to confirm the depth of vitreous freezing and the orientation of the specimens. Ultrathin sections from the Epon-embedded specimens were cut and doubly stained with uranyl acetate and lead citrate for morphological observation. Immunocytochemical staining was performed on ultrathin sections, which were embedded in Lowicryl K4M resin, by an immunogold method (CG particle size: $15 \mathrm{~nm}$ ). Briefly, ultrathin sections were cut and mounted on gold grids with a supporting membrane. Sections were labeled with a postembedding staining method using primary antibodies as mentioned above. The staining procedures were generally the same as at the light microscopic level, except for the use of CG as a visualizing marker $[28,29]$. Some anti-actin antibody staining sections were pretreated for antigen retrieval in a microwave at $95^{\circ} \mathrm{C}$ for 3 min. Finally, they were counterstained with uranyl acetate and Millonig's lead acetate. The sections were examined using a Hitachi H-7100 electron microscope at an $80 \mathrm{kV}$ accelerating voltage.

For experimental controls, the primary and/or secondary antibodies were omitted or replaced with BSA in PBS.

\section{Results}

\section{Light microscopic observation}

When stomach tissues were fixed successfully by rapid (propane)-freezing and freeze substitution, the tissues were stained clearly with hematoxylin and eosin. Immunostaining with the anti- $\alpha$ - or $\beta$-subunits of $\mathrm{H}^{+} \cdot \mathrm{K}^{+}$-ATPase antibodies labeled the tissues more intensely and clearly compared with chemically fixed tissues. The average $\mathrm{pH}$ values of the gastric juice were 2.0 in the fed group and 6.4 in the starved group. This means that gastric acid was actively secreted in the former while it was at resting phase in the latter. The parietal cells stained positively with anti- $\alpha$ - or $\beta$-subunits of $\mathrm{H}^{+} \cdot \mathrm{K}^{+}$-ATPase antibodies were scattered throughout the whole gland from the deep pit to the glandular base. On the secreting-phase specimens, these appeared as a contourlined apical surface and intracellular canaliculi with a brownish line. At the resting phase, diffuse cytoplasmic staining was found (Fig. 1a, b). The parietal cells in the secreting phase, which were located in the top one third of the gland, were densely stained with the anti-phosphorylated ezrin antibody. However, the anti-nonphosphorylated ezrin antibody hardly labeled those cells. In the resting phase, the anti-phosphorylated ezrin antibody showed a very weak reaction, while nonphosphorylated ezrin antibody caused no reaction (Figs. 2a-d, 3a, b).

\section{Electron microscopic observation}

When specimens were processed successfully by high pressure-freezing, good vitreous freezing occurred to a depth of at least $100 \mu \mathrm{m}$ from the cooled surface. On morphological observation, the specimens showed excellent ultrastructural preservation of each cell type in the epithelial layer. The parietal cells were well preserved with intracellular canaliculi and tubulovesicles. The former structures were clearly outlined and filled with numerous microvilli. The latter was observed as a developed tubulestructure mass. The nuclei and other cell organelles in the cytoplasm, such as actin filaments in the microvilli, were also well preserved. In the tissues freeze-substituted with acetone containing acrolein, the ultrastructures were also
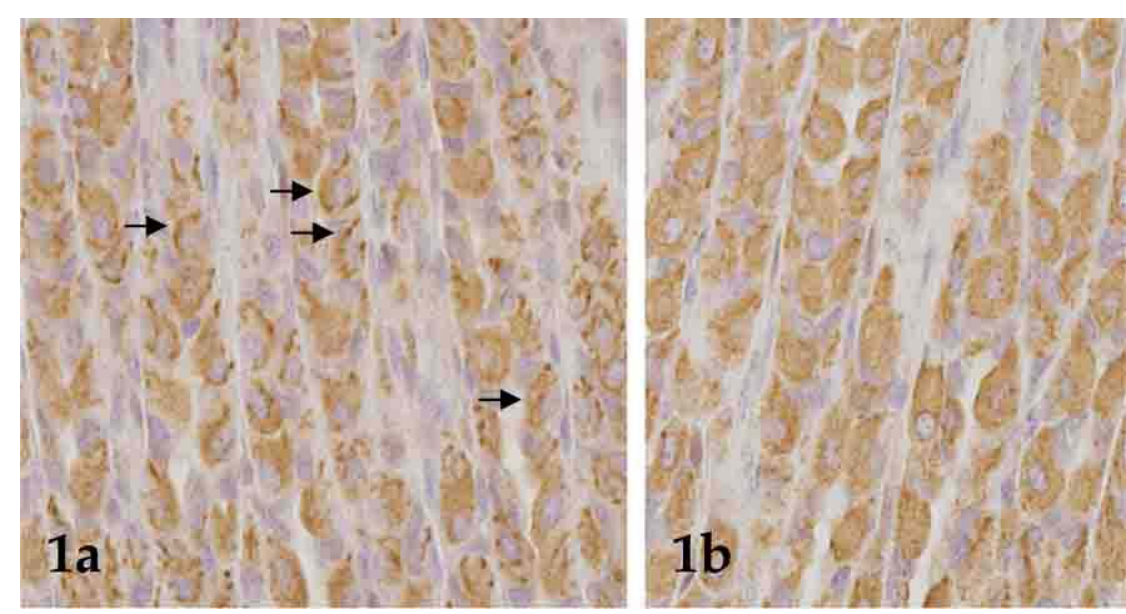

Fig. 1. Rat gastric gland immunostained with the anti- $\alpha$-subunit of the $\mathrm{H}^{+} \cdot \mathrm{K}^{+}-\mathrm{ATPase}$ antibody. Parietal cells from fed, secreting-phase rats (a) were intensely labeled. Intracellular canaliculi were clearly stained and appeared as thread-like structures (arrows). On the other hand, the staining was diffuse throughout the cytoplasm in the starved, resting-phase rats (b). 

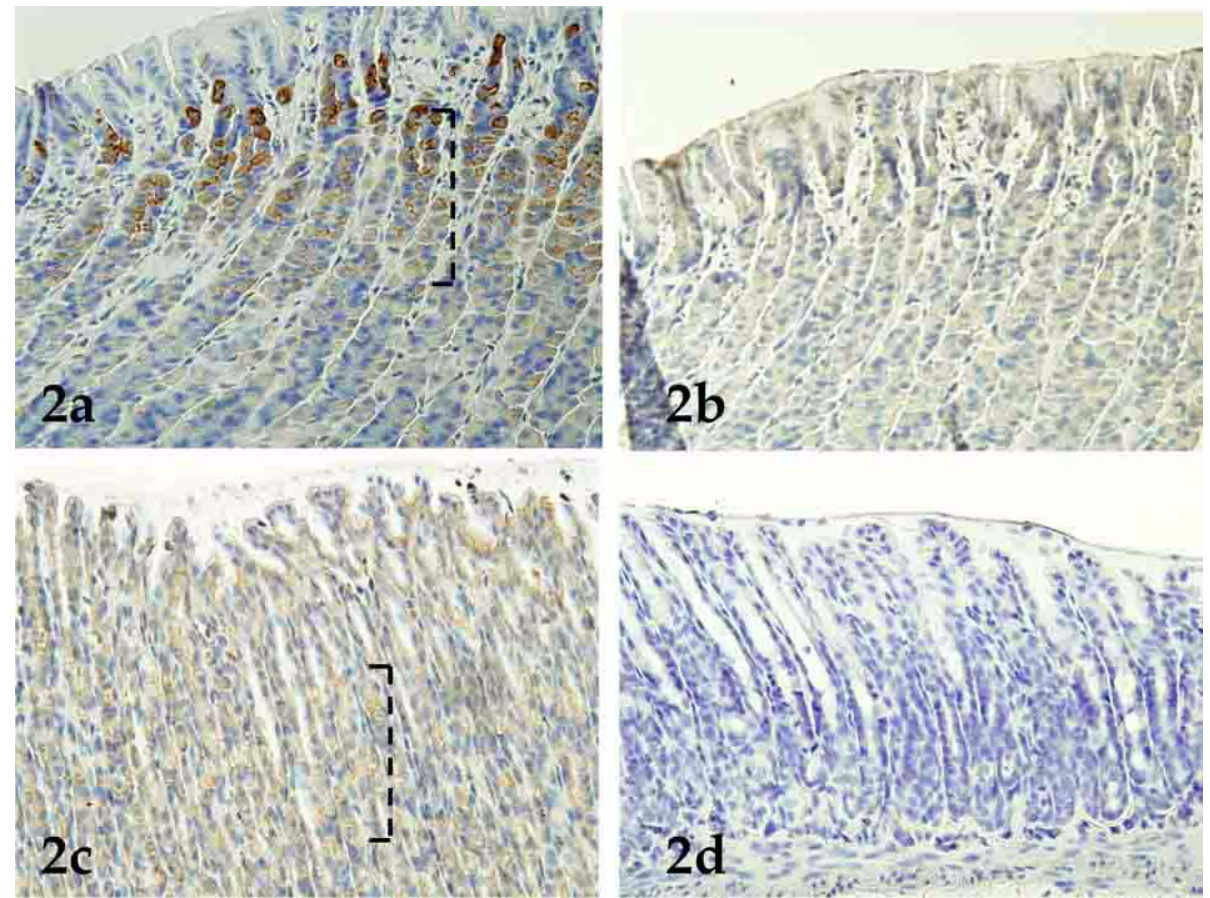

Fig. 2. Rat gastric gland immunostained with anti-phosphorylated ezrin (a, c) and anti-nonphosphorylated (b, d) ezrin antibodies. Specimens from the secreting phase (a) and resting phase (c) rats were labeled with the anti-phosphorylated ezrin antibody. The former was densely, and the latter very weakly, stained (shown in brackets). Especially in the former, the cells located in upper one third of the gland were heavily labeled. However, specimens from both phases (b and $\mathbf{d}$ ) were hardly stained with the anti-nonphosphorylated ezrin antibody.
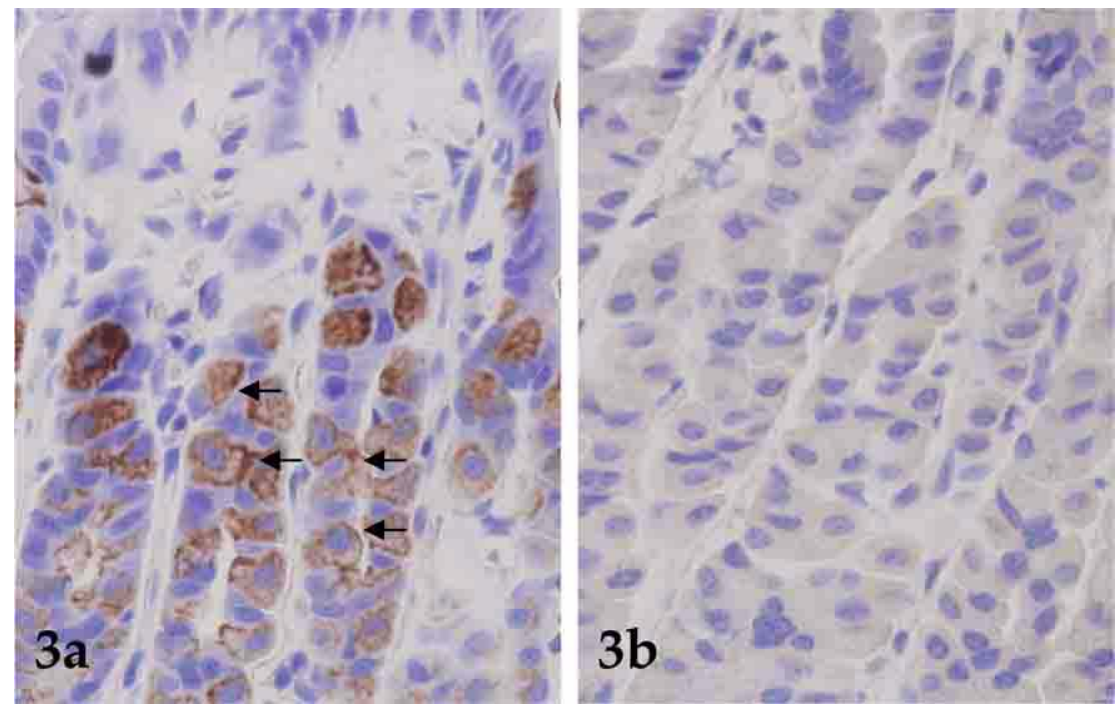

Fig. 3. Higher magnification of Fig. 2. Specimens from the secreting-phase were stained with the anti-phosphorylated ezrin antibody (a) but not with the anti-nonphosphorylated ezrin antibody (b). Cell membranes of parietal cells are densely contourlined with the brownish reaction products, while there was no discernible staining with the anti-nonphosphorylated ezrin antibody.

comparable to those found in specimens freeze-substituted with acetone containing osmium, except that the membrane was more obscure. The mitochondrial matrices and cytoplasm were electron-dense. In this study, it was found that the mitochondrial matrix showed high electron density not only in the specimens freeze-substituted with acetone containing osmium, but also in those freeze-substituted with the acetone containing acrolein (Fig. 4a, b). Further, we also observed a tubular structure similar to the connecting tubule described by Ogata $e t$ al. in the cell apex between the intracellular canaliculi and the tubulovesicular membrane system (data not shown) $[18,19]$. 

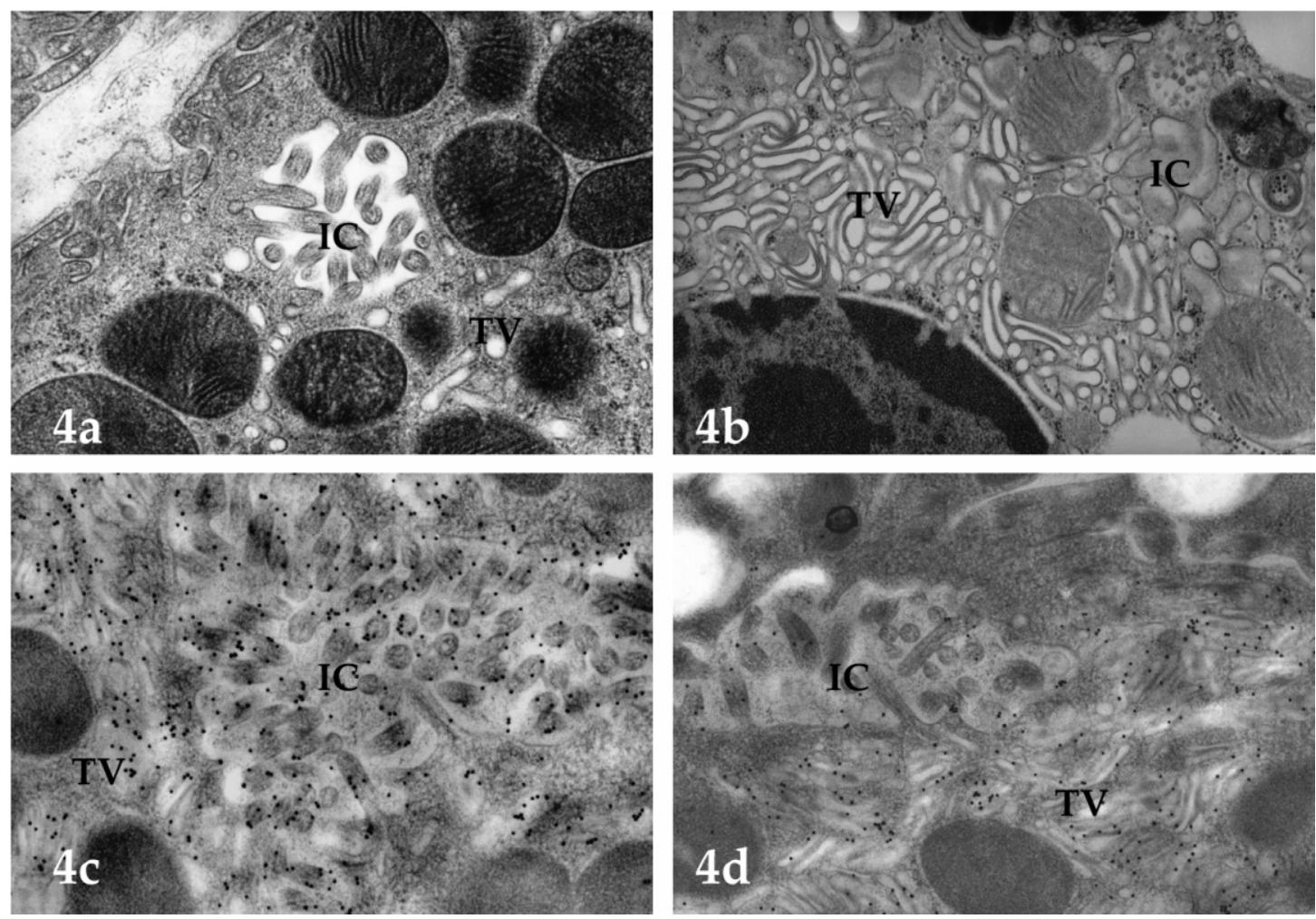

Fig. 4. A part of parietal cell from secreting-phase rat (a) and from resting-phase rat (b) was stained doubly with uranyl acetate and lead citrate. These cells showed excellent ultrastructural preservation using high pressure freezing followed by the freeze substitution method. Intracellular canaliculi (IC) with numerous microvilli were developed in the former, and tubulovesicles (TV) were markedly increased in the latter. These organelles were intensely labeled by immunogold-staining using the anti- $\alpha$-subunit antibody (c) and also the $\beta$-subunit antibody $(\mathbf{d})$ of $\mathrm{H}^{+} \cdot \mathrm{K}^{+}-$ ATPase.
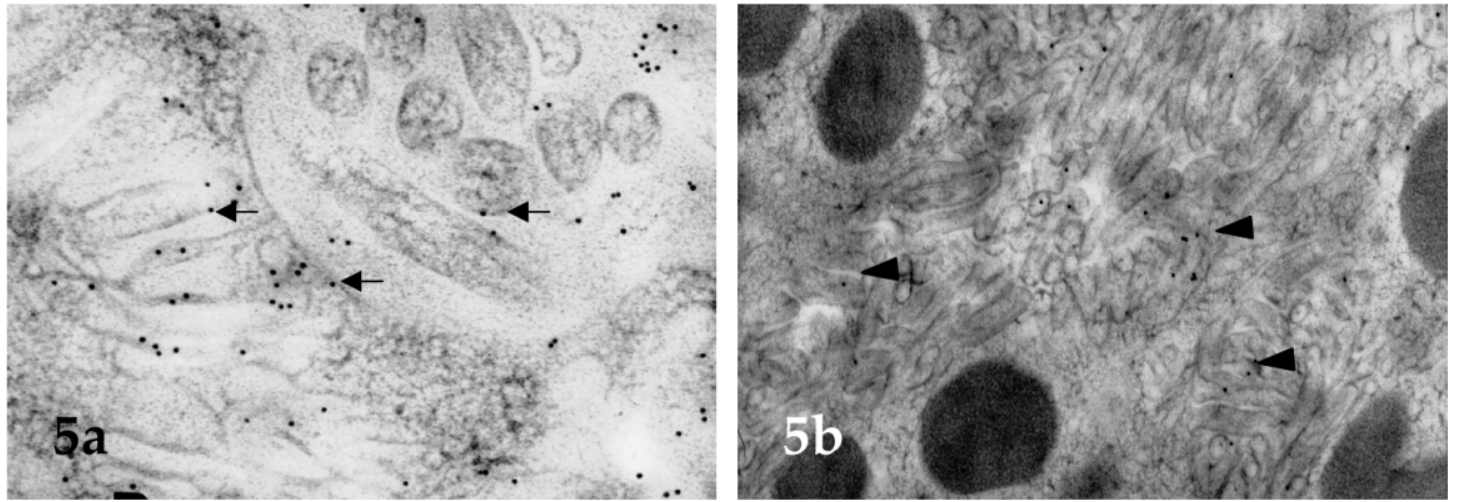

Fig. 5. A part of secreting-phase parietal cells immunogold-stained with anti-actin antibody (a) and with anti-phosphorylated ezrin antibody (b). The plasma membrane, microvillous membrane and tubulovesicular membrane were labeled with gold particles (in a, arrows). Antigen retrieval treatment using a microwave was performed prior to the anti-actin antibody staining, and the labeling density of immunostaining was stronger than that without pretreatment. The labeling of phosphorylated-ezrin was observed frequently on the microvillous membrane (in $\mathbf{b}$, arrowheads).

The specimens freeze-substituted in acetone containing $2 \%$ acrolein showed good structural preservation and were suitable for immunocytochemical observation. The immunocytochemical staining by anti-proton pump antibodies showed that $\alpha$ - and $\beta$-subunit molecules were distributed in a manner similar to intracellular canaliculous, microvillous and tubulovesicular membranes in the secreting phase (Fig. $4 c, d)$. These subunits were localized predominantly on the organelles in the resting phase, but somewhat more densely in the tubulovesicles (data not shown). Canaliculous and microvillous membranes were also stained with anti-actin antibody and anti-phosphorylated ezrin antibody in the 
secreting phase (Fig. 5a, b). Those membranes in the resting phase were weakly stained with similar antibodies. In contrast, anti-nonphosphorylated ezrin antibody did not stain any region in either phase.

\section{Discussion}

It is generally agreed that cryofixation allows superior preservation of ultrastructures and better retention of soluble components contained in cells and tissues than conventional chemical fixation $[5,17,27]$. In this study, the specimens cryofixed with rapid (propane)-freezing showed good morphological preservation and retention of soluble components at the light microscopic level. The immunostaining resulted in a clearer and denser reaction than that obtained with conventional chemical fixation. On the conventionally chemically fixed materials, it was not so easy to observe the structural changes in the cytoplasm at the light microscopic level. However, it was easy to discern these morphological differences on the cryofixed materials even at the light microscopic level (Fig. 1a, b). In addition, at the electron microscopic level, the ideal vitreous depth by high pressure freezing method reached a range of thickness of $100 \mu \mathrm{m}$ to $200 \mu \mathrm{m}$ from the frozen surface $[16,26,28,29]$. This means that the cells located in deep regions were fixed sufficiently and their ultrastructure could be examined without severe ice-crystal damage or loss of their immunocytochemical properties.

Parietal cells secrete hydrochloric acid and also intrinsic factors [25]. Gastric parietal cells are characterized by intracellular canaliculi with many microvilli and tubulovesicles in the cytoplasm [1, 15, 18, 19, 27-29]. Tubulovesicles are continuous to the intracellular canaliculi and change in volume according to fed or starved state. In this study, the average $\mathrm{pH}$ values of the gastric juice were 2.0 in the fed rats and 6.4 in the starved ones. This means that the ad libitum fed and starved states correspond to the active and inactive phases in hydrochloric acid secretion, respectively $[2,14,22,23]$. In previous immunocytochemical studies, we presented the subcellular distribution of $\mathrm{H}^{+} \mathrm{K}^{+}$ATPase using high-pressure frozen, freeze-substituted and resin-embedded tissues $[28,29]$. The anti- $\alpha$ - or $\beta$-subunits of $\mathrm{H}^{+} \cdot \mathrm{K}^{+}$-ATPase antibodies stained positively on the cells scattered throughout the whole gland from the deep pit to glandular base. It is considered that the $\alpha$-subunit is a catalytic domain, and the $\beta$-subunit is a modular domain $[3,24$, $30,31]$. Proton pump molecules are activated on the luminal surface membrane, including the intracellular canaliculi and microvillous membrane in the secreting state, while they become inactive in the tubulovesicular membrane of the cytoplasm in the resting state. In this study, the two subunits mainly showed the same distribution pattern on these cell organelles.

The parietal cells showed marked differences in ultrastructural features between the fed and starved states as mentioned above (Fig. 4a, b). In the secreting phase, intracellular canaliculi were extended while tubulovesicles shrank in the cytoplasm. On the other hand, in the resting state, the tubulovesicles spread all through the cytoplasm, but intracellular canaliculi were reduced in size. Jöns et al. reported that the linkage of actin and the plasma membrane is achieved only by the phosphorylation of ezrin molecules [7]. Namely, the ezrin molecules bind to actin filaments when they are phosphorylated and ezrin nonphosphorylated molecules are then scattered in the cytoplasm without actin binding. It is thought that the initiation of these morphological changes is induced by cytoskeletal actin, after which the ezrin-actin battery causes the transformation of parietal cells. The battery is activated by the phosphorylated condition of the ezrin molecules. Phosphorylated ezrin anchors actin to CD44 in plasma membranes. Thus, the actin binds to CD44 via ezrin on the plasma membranes, not in tubulovesicle membranes. This binding phenomenon cannot include tubulovesicles because the CD44 molecule is not part of the tubulovesicle membrane $[1,21,34,35]$. In our experiment, the anti-phosphorylated ezrin antibody staining was strong on parietal cells in the upper one third of the glandular depth in the active phase, while the labeling was very weak in the resting phase. No reaction of antinon-phosphorylated antibody staining was observed in the cells in either phase. Thus, actin filaments were bound to phosphorylated ezrin in the active phase, but ezrin was in a dephosphorylated condition in the resting phase. The phosphorylation of ezrin is controlled by cAMP [34, 35]. One possible explanation is that the phosphorylation of ezrin molecules is related to a reciprocal shift in the proton pump between the intracellular canaliculi membrane and tubulovesicles. To our knowledge this is the first report regarding the relationship between ezrin and actin interaction at the ultrastructural level. Further experiments are required to clarify the mechanism of gastric acid secretion.

\section{Acknowledgments}

We thank Mr. Satoru Imamura and Mr. Satoru Nonaka for their technical assistance. This work was supported in part by a Grant-in-Aid for Scientific Research (No. 15590164 to S.T.) from the Ministry of Education, Culture, Sports, Science and Technology, Japan.

\section{References}

1. Agnew, B. J., Duman, J. G., Watson, C. L., Coling, D. E. and Forte, J. G. (1999) Cytological transformations associated with parietal cell stimulation: critical steps in the activation cascade. J. Cell Sci. 112; 2639-2646.

2. Asano, S. (1997) Structure-function study on gastric proton pump. Yakugaku Zasshi 117; 379-393.

3. Chow, D. C. and Forte, J. G. (1993) Characterization of the betasubunit of the $\mathrm{H}^{+}, \mathrm{K}^{+}$-ATPase using an inhibitory mono-clonal antibody. Am. J. Physiol. 265; C1562-1570.

4. Graham, R. C. Jr. and Karnovsky, M. J. (1966) The early stages of absorption of injected horseradish peroxidase in the proximal tubules of mouse kidney. J. Histochem. Cytochem. 14; 291-302.

5. Heuser, J. B., Reese, T. S., Dennis, M. J., Jan, Y., Jan, L. and Evans, L. (1979) Synaptic vesicle exocytosis captured by quick freezing and correlated with quantal transmitter release. J. Cell 
Biol. 81; 275-300.

6. Ito, S. and Schofield, G. C. (1974) Studies on the depletion and accumulation of microvilli and changes in the tubulovesicular compartment of mouse parietal cells in relation to gastric acid secretion. J. Cell Biol. 63; 364-382.

7. Jöns, T., Heim, H.-K., Kistner, U. and Ahnert-Hilger, G. (1999) SAP97 is a potential candidate for basolateral fixation of ezrin in parietal cells. Histochem. Cell Biol. 111; 313-318.

8. Karam, S. M. and Leblond, C. P. (1993) Dynamics of epithelial cells in the corpus of the rnouse stomach. I. Identification of proliferative cell types and pin pointing of the stem cell. Anat. Rec. $236 ; 259-279$.

9. Karam, S. M. and Leblond, C. P. (1993) Dynamics of epithelial cells in the corpus of the mouse stomach. II. Outward migration of pit cells. Anat. Rec. 236; 280-296.

10. Karam, S. M. and Leblond, C. P. (1993) Dynamics of epithelial cells in the corpus of the mouse stomach. III. Inward migration of neck cells followed by progressive transformation into zymogenic cells. Anat. Rec. 236; 297-313.

11. Karam, S. M. (1993) Dynamics of epithelial cells in the corpus of the mouse stomach. IV. Bidirectional migration of parietal cells ending in their gradual degeneration and loss. Anat. Rec. 236; 314-332.

12. Karam, S. M. and Leblond, C. P. (1993) Dynamics of epithelial cells in the corpus of the mouse stomach. V. Behavior of enteroendocrine and caveolated cells: general conclusion on cell kinetics in the oxygenic epithelium. Anat. Rec. 236; 333-340.

13. Karam, S. M., Yao, X. and Forte, J. G. (1997) Functional heterogeneity of parietal cells along the pit-gland axis. Am. J. Physiol. 272; G161-G171.

14. Maeda, M. (1991) Biochemical studies on gastric $\mathrm{H}^{+}, \mathrm{K}^{+}$-ATPase. Seikagaku 63; 1037-1061.

15. Miller, M. L., Judd, L. M., van Driel, I. R., Andringa, A., Flagella, M., Bell, S. M., Schultheis, P. J., Spicer, Z. and Shull, G. E. (2002) The unique ultrastructure of secretory membranes in gastric parietal cells depends upon the presence of $\mathrm{H}^{+}, \mathrm{K}^{+}-$ ATPase. Cell Tissue Res. 309; 369-380.

16. Moor, H. (1987) Theory and practice of high-pressure freezing. In "Cryotechniques in Biological Electron Microscopy", ed. by R. A. Steinbrecht and K. Zierold, Springer-Verlag, Heidelberg, pp. 175-191.

17. Murata, F., Suzuki, S., Tsuyama, S., Suganuma, T., Imada, M. and Furihata, G. (1985) Application of rapid freezing followed by freeze-substitution acrolein fixation for cytochemical studies of the rat stomach. Histochem. J. 17; 967-980.

18. Ogata, T., Araki, K. and Yamasaki, Y. (1995) Ultra-high resolution scanning electron microscopic studies on the membrane system of the rat parietal cells after tetragastrin stimulation. Ital. J. Anat. Embryol. 100 [Suppl. 1]; 393-401.

19. Ogata, T. (1997) Gastric oxyntic cell structure as related to secretory activity. Histol. Histopathol. 12; 739-754.

20. Ogawa, K., Tsuji, M., Tsuyama, S. and Sasaki, F. (2003) Histamine increased the uptake of rhodamine 123 in mitochondria of living parietal cells in cultured gastric glands from starved guinea pigs. Acta Histochem. Cytochem. 36; 255-262.

21. Okamoto, C. T., Karam, S. M., Jeng, Y. Y., Forte, J. G. and
Goldenring, J. R. (1998) Identification of clathrin and clathrin adaptors on tubulovesicles of gastric acid secretory (oxyntic) cells. Am. J. Physiol. 274; C1017-C1029.

22. Pettitt, J. M., Toh, B.-H., Callaghan, J. H., Gleeson, P. A. and van Driel, I. R. (1993) Gastric parietal cell development: expression of the $\mathrm{H}^{+} / \mathrm{K}^{+}$-ATPase subunits coincides with the biogenesis of the secretory membranes. Immunol. Cell Biol. 71; 191-200.

23. Reenstra, W. W. and Forte, J. G. (1990) Isolation of $\mathrm{H}^{+}, \mathrm{K}^{+}-$ ATPase-containing membranes from the gastric oxyntic cell. Methods Enzymol. 192; 151-165.

24. Scarff, K. L., Judd, L. M., Toh, B.-H., Gleeson, P. A. and van Driel, I. R. (1999) Gastric $\mathrm{H}^{(+)}, \mathrm{K}^{(+)}$-adenosine triphosphatase beta subunit is required for normal function, development, and membrane structure of mouse parietal cells. Gastroenterology $117 ; 605-618$.

25. Shao, J. S., Schepp, W. and Alpers, D. H. (1998) Expression of intrinsic factor and pepsinogen in the rat stomach identifies a subset of parietal cells. Am. J. Physiol. 274; G62-G70.

26. Studer, D., Michel, M., Wohlwend, M., Hunziker, E. B. and Buschmann, M. D. (1995) Vitrification of articular cartilage by high-pressure freezing. J. Microsc. 179; 321-332.

27. Sugai, N., Ito, S., Ichikawa, A. and lchikawa, M. (1985) The fine structure of the tubulovesicular system in mouse gastric parietal cell processed by cryofixation method. J. Electron Micrcsc. 34; 113-122.

28. Tsuyama, S., Matsushita, S., Takatsuka, T., Nonaka, S., Hasui, K. and Murata, F. (2002) Cytochemical investigation of gastric gland component cells with high-pressure freezing followed by freeze-substitution and hydrophilic resin embedding. Anat. Sci. Int. 77; 74-83.

29. Tsuyama, S., Matsushita, S., Nonaka, S., Yonezawa, S. and Murata, F. (2003) Cytochemistry of gastric parietal cells with high-pressure freezing followed by freeze-substitution. J. Electron Microsc. 52; 145-151.

30. Tyagarajan, K., Chow, D. C., Smolka, A. and Forte, J. G. (1995) Structural interactions between $\alpha$ - and $\beta$-subunits of the gastric $\mathrm{H}^{+}, \mathrm{K}^{+}$-ATPase. Biochim. Biophys. Acta 1236; 105-113.

31. Tyagarajan, K., Townsend, R. and Forte, J. G. (1996) The beta-subunit of the rabbit $\mathrm{H}^{+}, \mathrm{K}^{+}$-ATPase: a glycoprotein with all-terminal lactosamine-units capped with $\alpha$-linked galactose residues. Biochemistry 35; 3238-3246.

32. Yang, D.-H., Kasamo, H., Miyauchi, M., Tsuyama, S. and Murata, F. (1996) Ontogeny of sulphated glycoconjugate-producing cells in the rat fundic gland. Histochem. J. 28; 33-43.

33. Yang, D.-H., Tsuyama, S., Ge, Y.-B., Wakamatsu, D., Ohmori, J. and Murata, F. (1997) Proliferation and migration kinetics of stem cells in the rat fundic gland. Histol. Histopathol. 12; 719727.

34. Yao, X., Cheng, L. and Forte, J. G. (1996) Biochemical characterization of ezrin-actin interaction. J. Biol. Chem. 271; 72247229.

35. Zhou, R., Cao, X., Watson, C., Miao, Y., Guo, Z., Forte, J. G. and Yao, X. (2003) Characterization of protein kinase A-mediated phosphorylation of ezrin in gastric parietal cell activation. J. Biol. Chem. 278; 35651-35659. 